\title{
Control Room Training for the Hyper-X Program Utilizing Aircraft Simulation
}

\author{
Jessica R. Lux-Baumann ${ }^{*}$ and Ray A. Dees ${ }^{\dagger}$ \\ NASA Dryden Flight Research Center, Edwards, California, 93523 \\ David J. Fratello* \\ Zel Technologies, LLC, Hampton, Virginia, 23669
}

\begin{abstract}
The NASA Dryden Flight Research Center flew two Hyper-X Research Vehicles and achieved hypersonic speeds over the Pacific Ocean in March and November 2004. To train the flight and mission control room crew, the NASA Dryden simulation capability was utilized to generate telemetry and radar data, which was used in nominal and emergency mission scenarios. During these control room training sessions, personnel were able to evaluate and refine data displays, flight cards, mission parameter allowable limits, and emergency procedure checklists. Practice in the mission control room ensured that all primary and backup Hyper-X staff were familiar with the nominal mission and knew how to respond to anomalous conditions quickly and successfully. This paper describes the technology in the simulation environment and the mission control center, the need for and benefit of control room training, and the rationale and results of specific scenarios unique to the Hyper-X research missions.
\end{abstract}

\section{Nomenclature}

$\begin{array}{ll}\text { AFB } & \text { Air Force base } \\ \text { AIP } & \text { initial point } \\ \text { ALCH } & \text { launch point } \\ \text { APWR } & \text { power transfer point } \\ \text { AREV } & \text { reverse point } \\ \text { BIT } & \text { built-in-test } \\ \text { CVT } & \text { current-value table } \\ \text { DECOM } & \text { decommutator } \\ \text { DFRC } & \text { Dryden Flight Research Center } \\ \text { EAFB } & \text { Edwards Air Force Base } \\ \text { EDW } & \text { Edwards } \\ \text { EP } & \text { emergency procedure } \\ \text { FADS } & \text { flush air data system } \\ \text { FMU } & \text { flight management unit } \\ \text { FTS } & \text { flight termination system } \\ \text { GMN } & \text { Gorman } \\ \text { GPS } & \text { global positioning system } \\ \text { GRIM } & \text { Global Real-Time Interactive Map } \\ \text { GVO } & \text { Gaviota } \\ \text { g } & \text { gravitational unit } \\ \text { HDOT } & \text { altitude rate } \\ \text { HXLV } & \text { Hyper-X Launch Vehicle (modified Pegasus }{ }^{\circledR} \text { rocket) } \\ \text { HXRV } & \text { Hyper-X Research Vehicle } \\ \text { INALT } & \text { inertial altitude } \\ & \end{array}$

\footnotetext{
${ }^{*}$ Test Information Engineer, Range Engineering Branch, M/S 3302, AIAA professional member.

${ }^{\dagger}$ Simulation Engineer, Simulation Engineering Branch, M/S 4840A, AIAA nonmember.

* Senior Aerospace Engineer, Zel Technologies, LLC, Hampton, Virginia, AIAA nonmember.
} 


$\begin{array}{ll}\text { LaRC } & \text { Langley Research Center } \\ \text { LBITOR } & \text { health summary bit } \\ \text { MCC } & \text { Mission Control Center } \\ \text { NASA } & \text { National Aeronautics and Space Administration } \\ \text { NAWC-WD } & \text { Naval Air Warfare Center Weapons Division } \\ \text { NZF } & \text { vertical acceleration, filtered } \\ \text { NZUF } & \text { vertical acceleration, unfiltered } \\ \mathrm{N}_{z} & \text { vertical acceleration } \\ \text { PAGE } & \text { Project Application Graphics Executable } \\ \text { PCM } & \text { pulse-coded modulation } \\ \text { PDS } & \text { Parameter Display System } \\ \text { SIM3DApp } & \text { an in-house software application } \\ \text { TIE } & \text { Test Information Engineer } \\ \text { TRAPS } & \text { Telemetry/Radar Acquisition Processing } \\ \text { VME } & \text { VERSAmodule Eurocard, a microcomputer bus } \\ \text { WATR } & \text { Western Aeronautical Test Range } \\ \text { WINGS } & \text { WATR Integrated Next Generation System }\end{array}$

\section{Introduction}

$\mathrm{T}$ he Hyper-X program was an experimental flight research program intended to demonstrate advanced hypersonic technologies. ${ }^{1}$ The primary research objective was to flight-test an airframe-integrated scramjet, which could pave the way for high-speed aircraft and the next generation of reusable launch vehicles. The NASA Langley Research Center (LaRC, Hampton, Virginia) was the Hyper-X program lead, and the NASA Dryden Flight Research Center (DFRC, Edwards, California) led the flight-test effort. Three Hyper-X Research Vehicles (HXRVs), collectively known as X-43A, were built for the Hyper-X program. All three vehicles were virtually identical; the main difference among them was the internal scramjet engine flowpaths. The first vehicle was intended to be flown to Mach 7 on June 2, 2001. It was destroyed along with its Pegasus ${ }^{\circledR}$ (Orbital Sciences Corporation, Dulles, Virginia) booster rocket approximately $48 \mathrm{~s}$ after launch because of a loss of control of the booster. ${ }^{2}$ The second vehicle was successfully flown to Mach 6.8 on March 27, 2004, and effectively demonstrated the in-flight operation of its scramjet. All of the goals for that mission, including positive acceleration of the vehicle by the scramjet, were achieved. The third and final mission of the program was flown to Mach 9.7 on November 16, 2004, again successfully demonstrating positive engine acceleration.

Control room training was an essential part of the preparation for all three Hyper-X missions. Previous work for flight 1 is described in Ref. 3. The state of the art for the 2001 first flight was further improved in the interim period before the 2004 flight 2 mission. This paper describes the control room training need, technological capability, and implementation philosophy for X-43A flights 2 and 3.

\section{Hyper-X Program Description and Training Need}

The HXRV was an unmanned vehicle that measured approximately $12 \mathrm{ft}$ long and $5 \mathrm{ft}$ wide, and weighed approximately 3,000 lb. A modified Pegasus ${ }^{\circledR}$ rocket booster known as the Hyper-X Launch Vehicle (HXLV), developed by Orbital Sciences Corporation of Chandler, Arizona, carried the X-43A to the test condition. The HXRV was mounted to the nose of the HXLV and the mated HXLV-HXRV stack was carried to the launch point under the wing of the NASA B-52 aircraft, tail number 008. After the B-52 aircraft took off from Edwards Air Force Base (EAFB), the stack was flown over the Pacific Ocean to approximately 40,000 ft and Mach 0.8 where it was released from the B-52 heading due west. A few seconds after drop, the HXLV rocket motor ignited, propelling the stack to a separation altitude of approximately 110,000 ft. After the HXRV separated from the HXLV, the engine cowl door on the HXRV opened, enabling engine ignition and operation for approximately $10 \mathrm{~s}$. After engine shutdown, the cowl door was closed, and an unpowered descent trajectory was flown to a splashdown in the Pacific Ocean. This flight trajectory is depicted visually in Figure 1. 


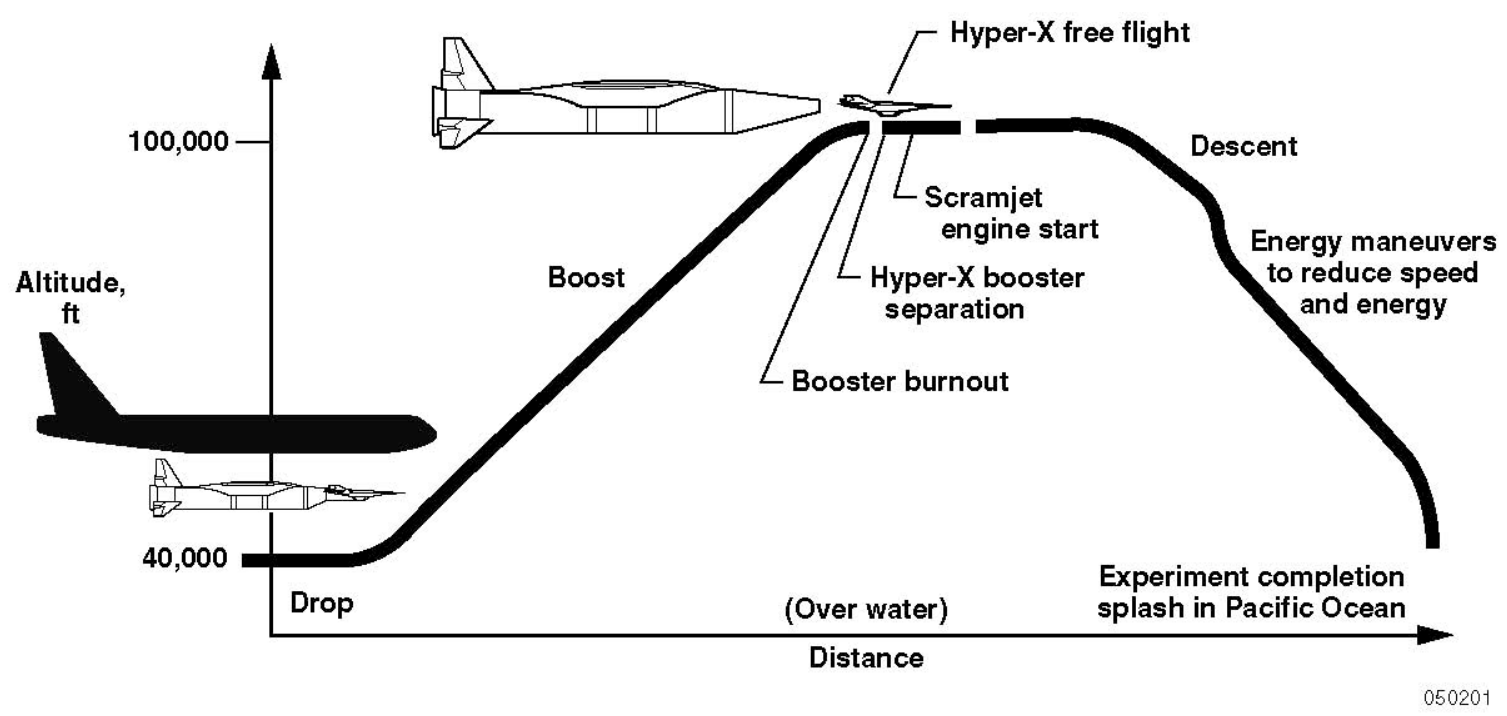

Figure 1. The X-43A flight trajectory.

The B-52, with the stack mated under its wing, took off from EAFB in the Western Aeronautical Test Range (WATR) of DFRC, with a transition to the Naval Air Warfare Center Weapons Division (NAWC-WD) Sea Range for the drop, boost, experiment, descent, and splashdown portions of the mission. The entire mission following the drop from the B-52 was carried out autonomously, and the HXRV was not recovered after splashdown. The expected flightpath over the NAWC-WD Sea Range was calculated so that any potential mission debris would land in designated weapons testing zones, which are free of boat traffic during NAWC-WD missions.

In order to launch the vehicle in the calculated hazard zones, the stack had to be dropped from the B-52 precisely within a 3-minute launch window while the B-52 was flying at Mach 0.8. To meet this launch objective, waypoints along the B-52 ground track from EAFB were defined. Mission planners from the DFRC Operations Engineering branch carefully defined activities during the 45-minute captive-carry flight to the launch point so that all in-flight vehicle preparations would take place on a timed schedule. These waypoints and the B-52 ground track are outlined in Fig. 2. The B-52 both originated and ended its flight at EAFB (noted by the EDW waypoint). Table 1 describes the activities onboard the B-52 along the B-52 flight profile. The entire research mission was controlled and monitored by the flight research team in the DFRC Mission Control Center (MCC). 


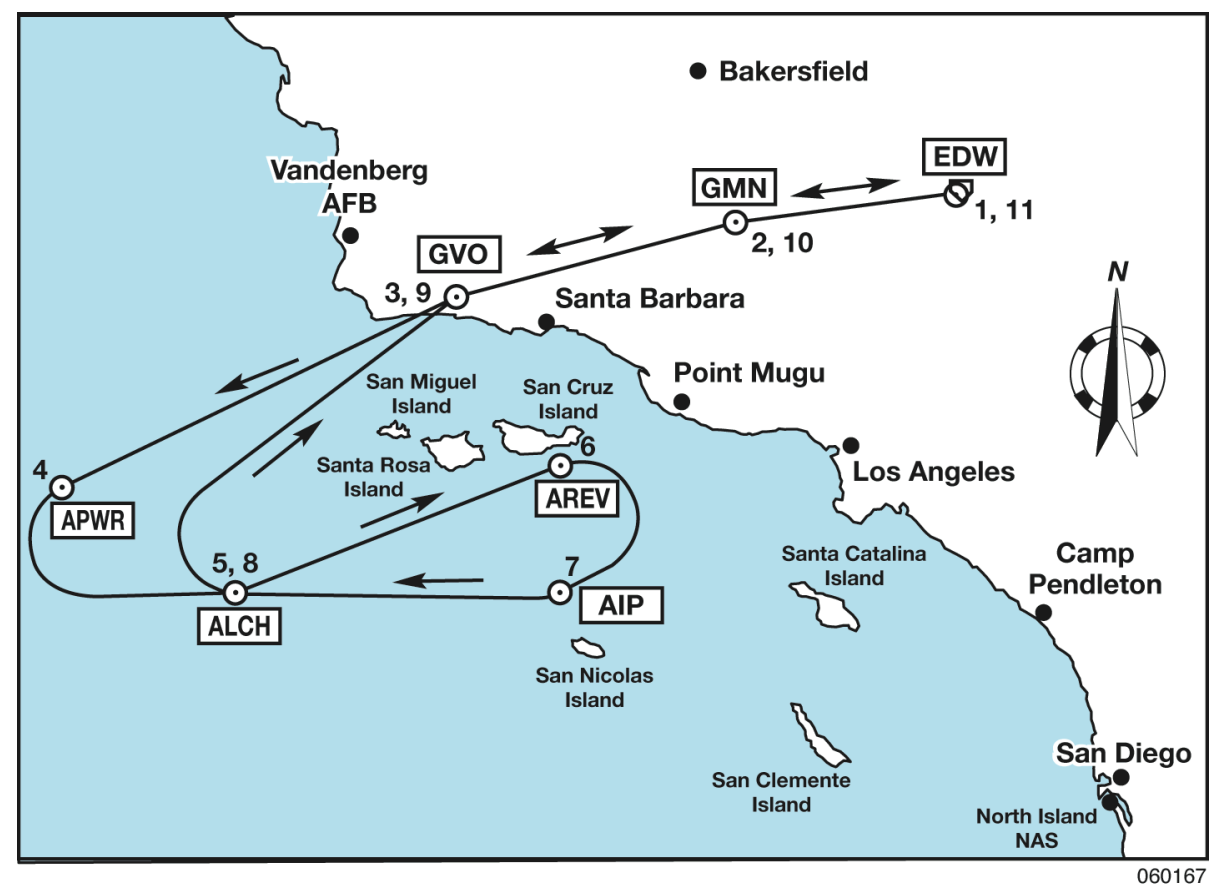

Figure 2. B-52 ground track and waypoints prior to HXRV launch.

Table 1. B-52 flight profile description and personnel responsibilities.

\begin{tabular}{|c|c|c|c|c|}
\hline \multicolumn{3}{|c|}{ Waypoint } & \multirow{2}{*}{$\begin{array}{l}\text { Mission } \\
\text { time } \\
(\mathrm{hh}: \mathrm{mm})\end{array}$} & \multirow[t]{2}{*}{ Functions performed before next waypoint } \\
\hline $\mathrm{t} \#$ & Label & Description & & \\
\hline 1 & EDW & $\begin{array}{l}\text { B-52 take-off from } \\
\text { EAFB }\end{array}$ & $00: 25$ & B-52 pilot performs phasing maneuvers \\
\hline 2 & GMN & Landmark & $00: 35$ & Transition from WATR assets to NAWC-WD Range assets \\
\hline 3 & GVO & Last over-land point & 00:44 & $\begin{array}{l}\text { HXLV FTS power on } \\
\text { HXRV power on, built-in-test, and power off }\end{array}$ \\
\hline 4 & APWR & Power transfer point & 00:56 & $\begin{array}{l}\text { HXLV FTS power transfer } \\
\text { HXRV system checks }\end{array}$ \\
\hline 5 & $\mathrm{ALCH}$ & $\begin{array}{l}\text { Launch point (in } \\
\text { reverse) }\end{array}$ & 01:04 & $\begin{array}{l}\text { Steady flight for HXLV engineers to monitor weather } \\
\text { conditions in the launch box } \\
\text { HXLV FTS tone checks }\end{array}$ \\
\hline 6 & AREV & Reverse point & 01:14 & HXRV system checks \\
\hline 7 & AIP & Initial point & $\begin{array}{c}01: 20 \\
(\mathrm{~L}-9)\end{array}$ & $\begin{array}{l}\text { Final B- } 52 \text { speed and altitude adjustments to achieve optimal } \\
\text { HXLV launch condition } \\
\text { HXRV system condition verification } \\
\text { HXRV and HXLV transfer to internal power } \\
\text { HXRV built-in test } \\
\text { Safety hooks and pins removed } \\
\text { HXLV fin actuation system power up and built-in test } \\
\text { HXRV valves uninhibited } \\
\text { HXRV Adapter cameras on }\end{array}$ \\
\hline 8 & $\mathrm{ALCH}$ & Launch point & 01:29 & $\begin{array}{l}\text { B- } 52 \text { pilot launches the HXLV on cue from DFRC MCC } \\
\text { Monitor stations onboard B-52 powered down }\end{array}$ \\
\hline 9 & GVO & Over-land point & $01: 42$ & Release NAWC-WD assets and return to WATR assets \\
\hline 10 & GMN & Landmark (in reverse) & 01:51 & \\
\hline 11 & EDW & Landing at EAFB & 01:58 & Post-launch task list \\
\hline
\end{tabular}


As Table 1 illustrates, the majority of the systems checks and maneuvers occurred in the launch-minus-9-minute (L9-minute) window between the initial point (AIP) and the launch point (ALCH). These actions included final B-52 heading, altitude, and speed correction directives; research vehicle internal battery, pressurized fuel system, and flight computer navigation-mode enabling; and launch vehicle battery squib, fin-pin, and fin-sweep activation. Operators onboard the B-52 performed these tasks, based on direction from the DFRC mission controller. Located in the DFRC MCC, the DFRC mission controller received inputs from the HXRV and HXLV chief engineers, who were receiving information from the research engineers monitoring the telemetered downlink data. For all waypoints, and for the last L-9 minute period in particular, these actions had to be carefully executed in order and on time, so that the B-52 arrived on condition at the designed launch box. Preflight operations for an X-43A mission took approximately seven days to complete (with some personnel staffing 24-hour shifts), so there was a big incentive to safely and successfully launch on the first attempt, which required the near-perfect execution of tasks during the B-52 flight profile. For this reason, extensive control room training was conducted to ensure the operator, the controller, and the engineer familiarity with the execution of their tasks.

During the B-52 flight to ALCH, control room engineers were expected to monitor vehicle health and status, reporting to the chief engineer that the systems were either on condition or that there was an anomaly. The project personnel defined a go/no-go list of parameters and values by which decisions to proceed to launch were made. Hyper-X Mission Control could not afford to launch this one-of-a-kind vehicle if any system was malfunctioning; conversely, each launch attempt cost approximately $\$ 500,000$, so there was incentive not to return to EAFB unnecessarily. Control room training is essential to ensure that everyone has internalized their portion of the go/nogo parameter set. There were personnel changes between each of the X-43A flights, and nearly a three-year downtime between flight 1 and flight 2, so training was needed to keep everyone proficient at their role. In addition, each station had a primary and a backup person, so control room training was required to ensure that both potential participants were comfortable in their role.

Emergency procedure (EP) checklists were on -hand in case project engineers noticed any of the possible flight hazards during the prelaunch phase of the B-52 flight profile. Some of the high risks during the B-52 flight included potential leaks in the HXRV fuel system, a fire in either the onboard HXRV silane system or the HXLV, and high wing loading on the B-52. Responses to these types of emergencies ranged from venting the HXRV fuel system or jettisoning the entire stack, to slowing the B-52 to reduce wing loading. As in the case of the go/no-go parameter set, execution of the emergency procedures had to be well-thought-out but initiated quickly, because of the risk to the flight crew, population centers on the ground, and mission hardware. Control room training is essential to ensuring crew familiarity with hazard conditions and the execution of emergency procedure response checklists.

Training was also performed in a captive-carry mission, in which the B-52 flies the expected profile with the HXRV and HXLV in a mated but not live condition. A captive-carry mission was performed prior to each of the three X-43A missions. This is, however, costly due to the WATR and NAWC-WD range assets [telemetry, radar, voice communications, flight termination system (FTS), and video systems] which must be scheduled to support the flight. Captive-carry missions are also high-risk, because flight hardware is being exposed to potential damage, and the B52 is being stressed by carrying the weight of the stack. It is not practical to perform multiple captive-carry missions. For this reason, a simulated training environment was required to prepare $\mathrm{X}-43 \mathrm{~A}$ operators, controllers, and engineers for the successful execution of mission tasks.

Using the X-43A simulation equipment, it was possible to generate a pulse-coded modulation (PCM) telemetry stream that exactly simulated the downlink telemetry stream, and send it to the MCC for display to end users. In this manner, the entire B-52 flight could be practiced, with simulated parameter values, so that participants could learn what to expect during a nominal flightpath. The simulated PCM stream also allowed for the injection of parameter failures, so that the X-43A team could practice executing emergency procedures. For control room training exercises, an extra person was used in the MCC. This training conductor was tuned in to the voice communications links between the mission controller and the B-52 operators, so that he could hear when commands had been issued or steps had been executed. The training conductor would then relay that command to the simulation engineer, so that the appropriate activity could be simulated in the parameter values in the PCM stream. 


\section{Simulation Environment}

The NASA Dryden Flight Research Center Research Aircraft Integration Facility (RAIF) and its simulation capabilities support the most advanced flight research projects through all phases of vehicle design, development, systems integration, verification, validation, and flight-test. A total of nine simulation labs offer data and communication interfaces to the aircraft test bays to accomplish combined systems testing. Data and communication interfaces are also provided to the Dryden MCC supporting combined system testing, control room training, and mission planning.

The NASA Dryden HXRV simulation was primarily developed to support verification and validation (V\&V) of the Hyper-X avionics. The HXRV simulation is a complex six-degree-of-freedom (6-DOF) simulation including models for aerodynamics, engine, control system, and actuators. Modifications were made to the simulation to support control room training by flying a predefined B-52 flight profile.

When the simulation is used for control room training, the following physical equipment is utilized (see Fig. 3).

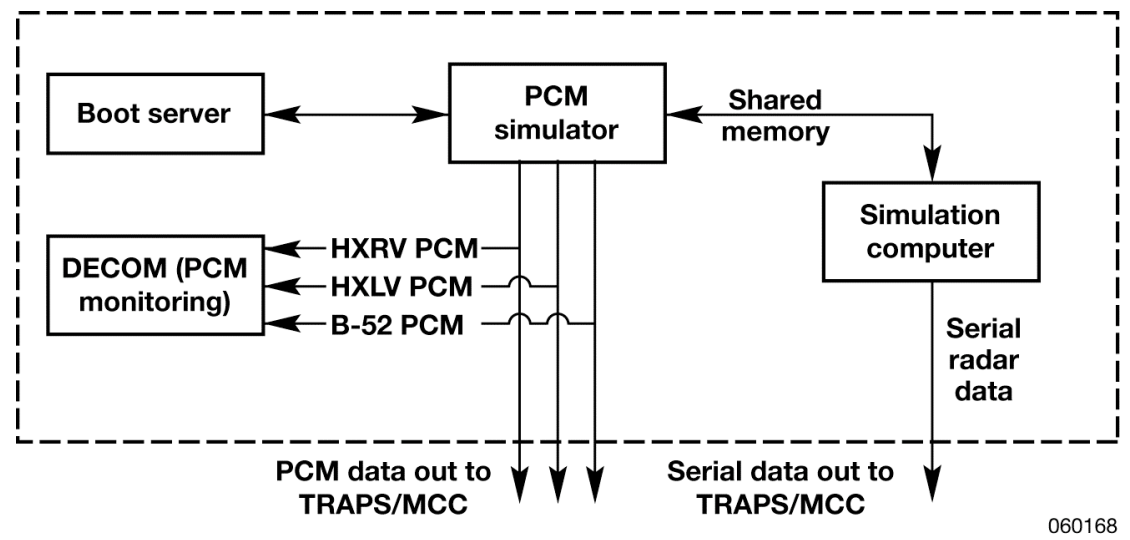

Figure 3. HXRV simulation data flow for control room training purposes.

For the Hyper-X missions, three PCM downlink streams were simulated (HXRV, HXLV, and B-52). To simulate these streams of data, a VERSAmodule Eurocard (VME) chassis containing three PCM simulator/encoder cards was added to the simulation configuration.

Data from the simulation is transferred to the VME chassis through a replicated shared-memory interface. This interface provides for the sharing of information between different operating systems and hardware platforms. The simulated PCM data consists of approximately 700 parameters (out of a total of approximately 2100 for the three Hyper-X PCM streams). Parameters not actively modeled in the simulation were simply assigned nominal values which they retained unless perturbed by an emergency procedure scenario. A problem to be faced in simulating PCM data is the requirement to convert the desired engineering unit output to counts. For linear calibrations, an inverse calibration can be directly obtained. For higher order calibrations, the Newton-Raphson method is used to numerically invert the polynomial. This technique is described in Ref. 4.

In addition to the PCM downlink data, the position of the B-52 is tracked by the WATR radar. To simulate this data stream, the simulation used one of the serial outputs of the simulation computer to send simulated radar data to the MCC. The radar data consists of the simulation of a single radar site within the WATR. This data is computed in the simulation from the latitude, longitude, and altitude of the aircraft. This data is transmitted out of the simulation via a serial (RS-232) data line, with an output rate of $20 \mathrm{~Hz}$ to match radar processing rates.

The flight profile of the B-52 was simulated by predefined latitude, longitude, and altitude values for the aircraft position as a function of time. This permitted simulations from aircraft takeoff, to the launch point, and to a landing back at EAFB. In addition, the simulation could be started at any point in this flight profile - for example, to focus on a particular phase of the mission. 
The use of scenario-based simulation scripts provided the flexibility necessary to introduce simulated failures and events at arbitrary times. For example, a scenario script was used to accomplish the vehicle pass/no pass builtin-test (BIT) of the HXRV's flight management unit (FMU) for flight-surface actuation, in response to a call for that operation from the mission controller. All of the scenario-based scripts contain predefined sequences of operations (usually the assigning of vehicle parameter data for output via the PCM data streams). The scripts include built-in delays to simulate real world events. Each scenario was coded into a single script with a corresponding reset script. Close coordination with the training conductor via the voice network was required to properly execute scripts at critical times.

\section{Mission Control Center Environment}

The MCCs are an asset in the WATR at DFRC. Dedicated lines from WATR telemetry and radar equipment provide input to the Telemetry/Radar Acquisition Processing System (TRAPS) facility, which processes data for transmission to the MCCs, where it can be displayed to project engineers. In the case of a control room simulation mission, the TRAPS input is switched to use PCM and serial radar data from the HXRV simulation environment via dedicated fiber lines from the RAIF. Hyper-X missions for vehicles 2 and 3 utilized the TRAPS in the WATR Integrated Next Generation System (WINGS) 1.8 configuration. Further detail on the WINGS phased development approach can be found in Ref. 5. A block diagram of the data flow between the aircraft, TRAPS, and MCC is shown in Fig. 4.

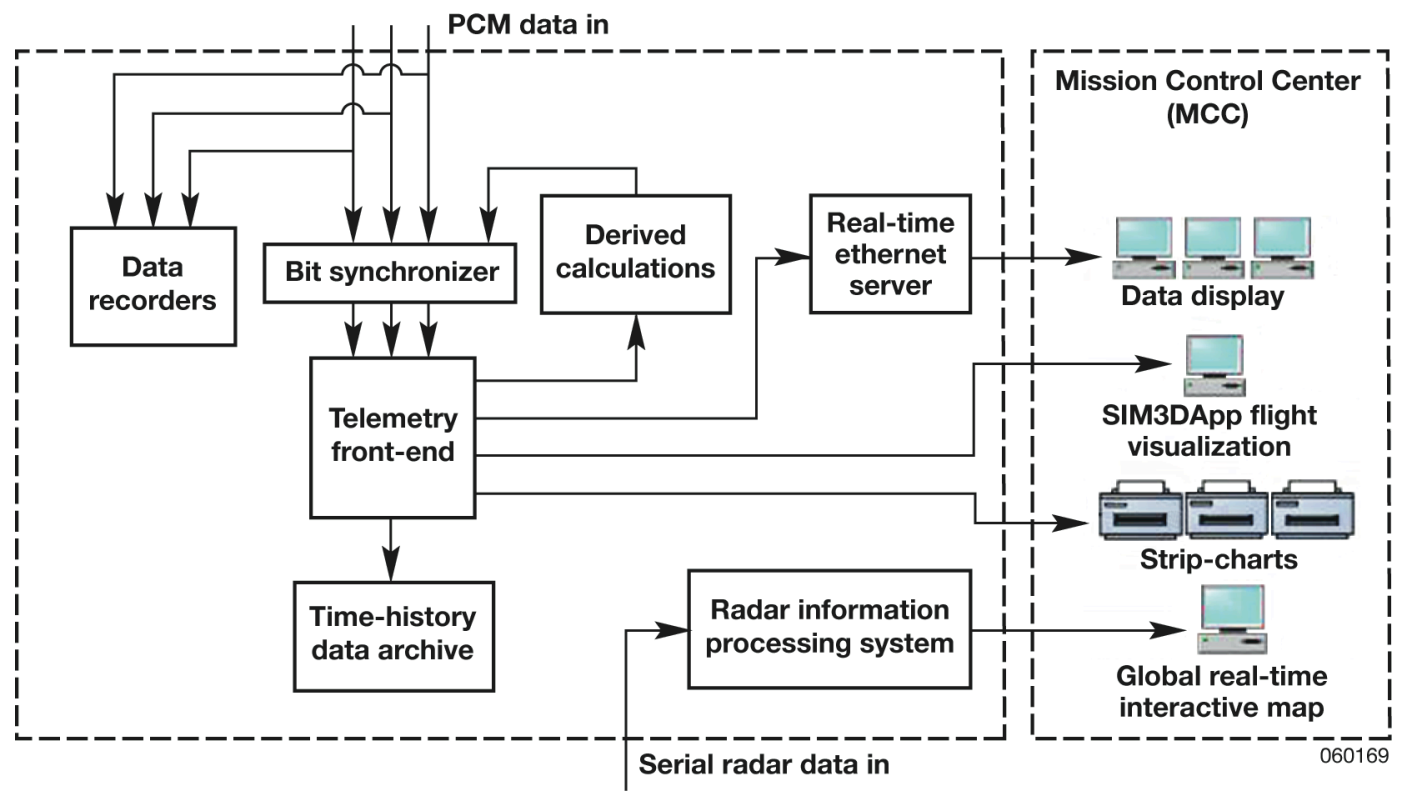

Figure 4. Data flow between data source, TRAPS, and MCC.

The WINGS 1.8 system utilizes a Wyle Laboratories (El Segundo, California) Omega telemetry front end. Calculations on telemetry parameters to create new derived parameters are performed using two in-house software applications (one running at rate on every data sample, and a second legacy program running on a subsample of the data set). Derived calculation code was incorporated in the HXRV simulation so that the desired control room training values of the derived calculations could be produced in the simulation environment.

Within the WINGS 1.8 system, all PCM and radar data is recorded on magnetic analog tape drives. It is also recorded in digital archive format so that it can be converted into time-history data and stored for long-term retrieval on DFRC internal flight data servers.

The MCCs in the WINGS 1.8 system offer a suite of in-house software programs for displaying flight data. The parameter display system (PDS) is a quickly reconfigurable software application that displays parameter values from a current-value table (CVT). Common data display types in PDS include numeric readouts of parameter values, color light boxes indicating parameter state, message words based on discrete parameter values, bar graphs, and time history displays. A second CVT-based application, PAGE (Project Application Graphics Executable) is utilized 
when enhanced graphic display capabilities are required. For the X-43A project, PAGE displays included visualization of fluids states and levels, and three-dimensional sketches of the HXRV with contour shading to represent temperature and pressure conditions at different locations on the vehicle. If parameters are required at rate (not sampled through a CVT), they are displayed on a physical strip-chart in the WINGS 1.8 MCC configuration. The two MCCs utilized for X-43A missions contained a total of eighteen eight-channel strip-charts at engineer workstations. For Hyper-X missions, a total of 51 PDS displays and sixteen PAGE control room displays were maintained by the WATR and viewed by project personnel during missions.

In addition to the display of telemetry and derived parameters, the WINGS 1.8 configuration provides a Global Real-time Interactive Map (GRIM). The GRIM utilizes radar and aircraft data to display an aircraft's location on a world map. Within the GRIM, custom restricted areas can be predefined on the world map. For the X-43A project, all of the waypoints were entered in the GRIM so that the mission controller could monitor success in passing each waypoint on condition as well as estimate arrival time at the next waypoint. In addition, the X-43A launch box and hazard debris areas over the Pacific Ocean were displayed. Range safety personnel utilize the GRIM to predict areas of impact in the event of FTS activation.

The X-43A missions also employed a dedicated in-house application called the Sim3DApp. This program received a broadcast of HXRV parameters from a server application running on the TRAPS front end. The Sim3DApp uses aircraft data to display a three-dimensional visual image of the B-52, HXLV, and HXRV in flight. Due to the high speed and altitude of the HXRV experiment, optical tracking was only available for the beginning of the rocket boost phase. The Sim3DApp was the only visualization of the separation, experiment, and descent parameter identification maneuvers (PID) available for the X-43A program.

The MCCs at DFRC are equipped with over 20 stations running either PDS, PAGE, or GRIM. Overhead video monitors are provided, and communications panels are available at every workstation to provide voice networks between research engineers, the mission controller, the chief engineers, pilots and operators onboard aircraft, the simulation engineer (in a training situation), and WATR operations personnel.

\section{Control Room Training Sessions}

Everyone who had a role in the B-52 flight and HXLV-HXRV stack launch participated in X-43A control room training exercises: the mission controller, the HXRV and HXLV chief engineers, the discipline engineers, the range control officer (RCO), the range safety officer (RSO), the test information engineer (TIE), the WATR equipment operators, the B-52 pilot, the B-52 onboard launch panel operator (LPO), and the B-52 onboard HXRV station operator (RV). Discipline engineers in the MCC included aerodynamics, flight systems, propulsion, instrumentation, guidance, navigation and control, and structures personnel for the HXRV, as well as HXLV development and integration engineers.

Additionally, two other people were necessary for the control room training exercises: the simulation engineer and the training conductor. A dedicated voice network between the training conductor and the simulation engineer was established to coordinate the execution of training scenarios. No one else in the room could hear this voice communication, so there was an element of surprise if an emergency situation was introduced by the training conductor.

Prior to flight 1, two EP training sessions were conducted using the technology described in Ref. 3. The Hyper-X solution detailed in Ref. 3 was put together in a limited timeframe of only a few months, with a very limited budget. The simulation capability at the time did not generate a PCM stream; rather, a computer in the TRAPS generated and broadcast over Ethernet directly to the PDS and PAGE displays. The GRIM and strip-charts in the control room could not be used because there was no simulated radar stream and no telemetry counts were received in the front end for conversion and display on strip-charts. No data recordings or postflight data could be generated from this method of control room training. In the nearly three-year downtime between flights 1 and 2, the DFRC simulation engineering branch was able to procure PCM simulator cards and develop the capability to send a simulated PCM stream to the TRAPS directly from the HXRV simulation environment. The capabilities described herein mark an improvement upon the capability for flight 1: engineers are now able to view simulated strip-charts and GRIM data, and simulated sessions can be recorded for postflight analysis. In addition, the simulated PCM stream allows for the operation of the Sim3DApp for flight visualization. As a side benefit, a more complete set of the operational equipment is utilized by this new method so it can be verified and personnel can gain experience. 
Prior to flight 2, a total of seven control room training sessions were held using the HXRV simulation. Between flight 2 and flight 3, an additional six control room training sessions were held. Each session lasted between two and four hours. Each session began with a nominal takeoff scenario for the B-52. After the simulated takeoff, however, the makeup of the training session was markedly different, depending on whether the training had been designated as nominal or an EP session. Prior to each EP training session, the training conductor and mission controller identified training goals and specific team training topics. The actual content and timing of the emergency scripts that were eventually developed for each EP training session, however, were known only to the training conductor and the simulation engineer. The X-43 mission controller was in training himself, and was not forewarned of simulation events, as everyone else on the team.

Within each EP training session, a progression of emergency scripts was run concurrent with the preprogrammed nominal simulation. The script would typically change specific parameters and eventually time out with one parameter or more in excess of their allowable go/no-go values. The EP scenarios were designed around, among other things, failed pressure sensors, a failed accelerometer, leaking valves, a hot telemetry transmitter, oxygen incursion within the HXRV, a fire within the HXRV, short-circuited battery systems, failed actuator linkages, and a structurally failed pylon hook.

The discipline engineers responsible for monitoring specific parameters would react to the simulated emergency with a call to their respective lead engineer. If the lead engineer concurred, he or she would report the situation and the suggested EP to the mission controller for formal execution of the steps. The EPs resulted in either the continuation of the flight, an abort of the drop and a recycle attempt, or a mission abort and a return-to-base call to the B-52. After meeting this final condition, the simulation would be paused for discussion of the scenario. Typically, a single EP scenario, from the start of the script to the pause of the simulation, could last as long as 10 to 20 minutes. It was not uncommon, particularly if the EP script had exposed some procedure deficiency or confusion in communication protocol, for the discussion to last as long as the EP scenario itself.

\section{Experience With Control Room Training Scenarios}

To make the best use of the control room training time, the team held roundtable discussions to learn and refine the mission EPs. The scenarios were designed by the training conductor to test the team's knowledge of the EPs and go/no go lists. An example of a typical control room EP scenario as developed by the training conductor is shown in Table 2. Table 2 represents the way in which the scenario was documented to the simulation engineer, who took this information and generated a script for the simulation environment. This particular scenario involves a subtle, and quite unlikely, failure of a solid-state accelerometer within the FMU. This was designed specifically to train the controllers to maintain vigilance on the less obvious failure parameters. The layout of Table 2 shows the general timing used during a typical script. It also illustrates that different parameters were altered during the script to simulate some real-world change as a result of the specific failure being simulated. 
Table 2. Emergency procedure scenario example.

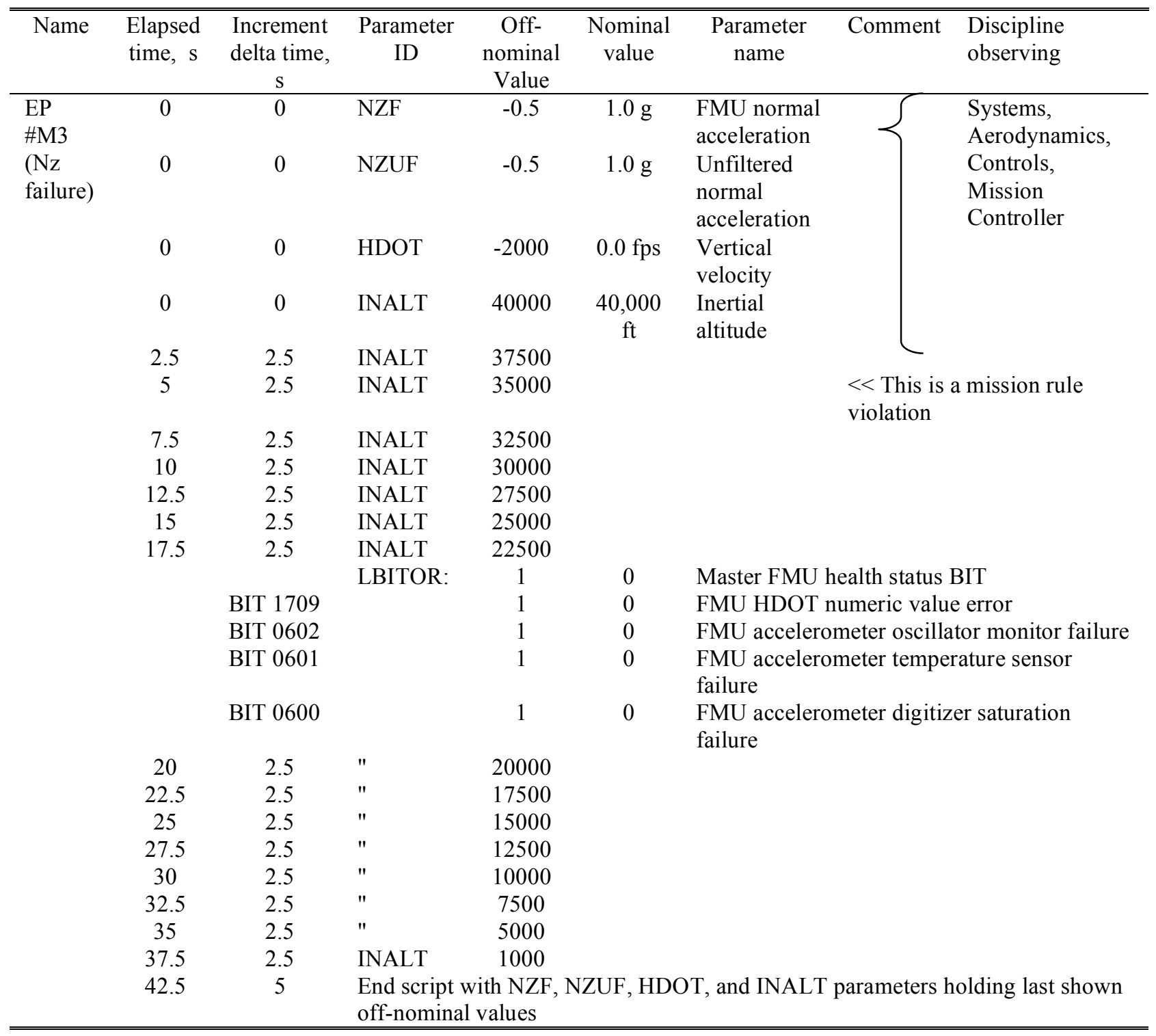

In addition to standard parameter failures, another level of EP scenario was introduced that simulated a failure that did not technically violate the go/no-go procedures. For example, in the case of multiple and closely related sensors, the failure of one out of the set was permissible. In one scenario, instead of simulating an oxygen (O2) incursion within the HXRV with a number of different $\mathrm{O} 2$ sensors showing over-limit $\mathrm{O} 2$ percentages, only a single $\mathrm{O} 2$ sensor was shown to go over the mission limit, and its value immediately jumped to the maximum value. While the initial urge might be to declare an emergency due to oxygen incursion, the correct response was actually that the vehicle had a single bad sensor and as such the go/no-go rules were not violated. Similar scenarios were designed around a single defective fire sensor and a single defective temperature sensor.

Another form of EP scenario focused on exploring subtle aspects of the official EPs. One major safety concern was the health of the pylon holding the X-43A stack onto the B-52. If there was an unsafe condition over land, the procedures called for a mission abort and jettison of the pylon (with the X-43A stack still attached) in a remote desert area. In the scenario concerning this mission rule, the B-52 onboard HXRV station operator was told to report that he had indication of "two pylon lights on." These lights are not monitored on ground displays, and indicated a 
serious problem within the pylon. This emergency was simulated at the L-5-minute point, during an extremely busy time onboard the B-52 and in the MCC. The immediate reaction in the MCC was to abort the drop and begin preparation for the B-52 to jettison the stack. However, since the call was made while the flight was over the Sea Range, the correct procedure for this case was to continue with the nominal drop mission and to jettison the pylon sometime after the drop. When this same scenario was repeated at a later session the mission controller correctly acknowledged the issue, and proceeded with the nominal predrop procedures.

One EP scenario resulted in a considerable amount of postscenario discussion. It involved a script that had the Sband telemetry transmitter temperature increase significantly, but never exceed the maximum allowed limit of 180 degrees $\mathrm{F}$. Then it cooled down and randomly fluctuated to represent a noisy signal, right around the parameter's go/no-go value of 140 degrees F. This scenario was run at about the L-8-minute point and resulted in the responsible engineer aborting the flight. The key, however, was that the script terminated with the transmitter's temperature static at 139 degrees F, an allowable temperature according to the mission go/no-go rules. Although no one could dispute the engineer's decision, the scenario created considerable discussion about the "what-if"s" of this situation. Many thought it more hazardous to the mission to be needlessly overcautious and return to EAFB for a later attempt, rather than continue the flight with a tolerable (according to the mission rules) instrument problem. Although this particular scenario does not have a straightforward solution, it benefited the team by exposing personnel to a possible scenario, creating an opportunity for them to evaluate their response to this situation.

As mentioned earlier, the L-9-minute period was the most critical for executing the HXRV launch, so all training sessions typically included repeated L-9-minute runs to get the entire team not only complying with the required pace but actually improving the clarity of their communication and getting comfortable with the critical procedural timing. Of course, these L-9-minute runs also provided a prime opportunity for the training conductor to implement EP scenarios to enhance the stress on the team, and to challenge their compliance with communications protocols during this communications-heavy period. One particularly challenging EP scenario, initiated by the training conductor at L-3 minutes, presented an intentional decrease in instrument battery voltage combined with an increase in S-band transmitter temperature. Neither of these scenarios was intended to cause initiation of an EP; rather, they served as a distraction for the already busy flight systems team. The actual emergency situation was the intermittent change in a critical status word that relates to the activation of the valves onboard the HXRV. This situation occurred at L-20 seconds and required a mission abort call from the lead flight systems engineer, which was correctly handled in the training session. Scenarios such as this helped the personnel stay focused and perceptive, and to communicate with clarity in the face of a highly stressful situation such as they might face on the actual day of the flight.

Other EP scenarios were specially designed to simulate unusual failures within the MCC infrastructure. These non-software-driven failures forced the team, and particularly the lead discipline engineers and the mission controller, to experience the situation live and later discuss the best methods to resolve the situation. For example, the intermittent loss of the telemetry link from the B-52 or X-43A was simulated with a technician literally pulling and reinserting the main PCM data input cable that was used to ultimately drive the displays in the control room. In one scenario, the electronics box controlling audio communications to a lead engineer was totally disabled. In another case, a lead engineer's key graphic display was shut down. To accentuate the stress, and simulate a worstcase event, each of these latter two events were performed with no forewarning and were timed to occur just prior to that key individual's team experiencing an EP scenario that was specifically focused on their discipline.

An interesting training phenomenon was noticed by the training conductor near the end of the training for flight 2. When the final training session was announced as a nominal session it was noted that several members of the mission control team seemed to be complacent - they didn't bring their EP books to the mission control center. Clearly there was zero expectation of any emergency events during the nominal training. Could this expectation affect training, and ultimately team performance?

The answer to this question was yes, as quickly demonstrated by an improvised test near the end of that session. The training conductor unexpectedly inserted an emergency script that simulated a no-go increase in S-band transmitter temperature just prior to the "nominal" launch. Neither the responsible engineer monitoring that display nor the chief engineer also overseeing the same data, reported the anomaly, and instead allowed the mission controller to proceed with the launch. During post-session discussions they both stated that they did indeed see the no-go data but regarded it as a computer simulation anomaly because "this was a nominal training." 
The training received during the nominal and emergency training sessions was excellent. But this "nominal" conduct during a session with "nominal" expectations, in the face of data to the contrary, seemed somewhat counterproductive to the goal of training. As a result, it was recommended and implemented that all future sessions be announced as simply mission training sessions. Except for the mission controller, who aided the training conductor with the determination and prioritization of training issues and goals for each session, the team wouldn't know if the training session was an EP or a nominal session. The result of this slight change to the training was clearly demonstrated just prior to flight 3 during a full nonstop 90-minute (and therefore assumed nominal) training session. At L-1 minute (with no foreknowledge to anyone in the MCC) a go/no-go battery issue was simulated and the flight systems lead engineer immediately called the emergency and an abort, and the entire team responded with the appropriate emergency procedural call-outs. It was an excellent rehearsal and demonstrated that the team was ready for flight.

\section{Control Room Training Benefit}

The Hyper-X project personnel reaped numerous benefits from the extensive control room training sessions that were conducted prior to flights 2 and 3. Due to the infrequent flights and months of downtime between missions, control room training was essential to providing the project personnel with recent experience and familiarity with the control center. Everyone participating became more familiar with the pace of operations and the time allotted for each step in the flight cards. Inexperienced personnel used training to get accustomed to the monotony of monitoring virtually static displays for over an hour as the B-52 flew offshore to the drop point. Development of crew discipline and focus was noticeable as multiple training sessions were conducted. Unlike the major portion of the B-52's flight, the final nine minutes immediately preceding the drop event were communication- and action-intense. This L-9minute portion of the flight was rehearsed repeatedly in both the nominal and the EP training sessions. In some cases, the practice revealed areas where a reassessment of the timing or execution of steps was required, and the flight cards were fine-tuned. Revisions of the flight cards were produced between each of the early control room training sessions as lessons learned from the exercise were incorporated into the cards.

In addition to fine-tuning the flight cards, project personnel were able to refine the go/no-go list and the EP checklists based on the control room training sessions. When the training conductor triggered a return-to-base call based on specific parameter temperature or pressure limits from the go/no-go list, in many cases a lengthy discussion on the true hard limit for that parameter would occur, and the project was able to perfect the allowable ranges of mission parameter values. It would be unacceptable for a debate on a mission parameter limit to take place during an actual mission; repeated testing of the limits in a training session allowed for preflight debate and discussion on appropriate mission parameter limits. Also, in one training session, a pressure over-limit call to vent the onboard systems was initiated by someone outside the propulsion group based on a review and misinterpretation of the data values displayed. This prompted a discussion by the group, and as a result, the Hyper-X team redefined the allowable initiators of EPs based on this experience in the training environment. Crew members also identified a need to speak succinctly and present information to the mission controller in a standard order every time, so an abbreviated language about EPs was born out of the practice in the control room training sessions. Repeated emergency scenarios in the final L-9-minute commotion helped the personnel practice staying focused, perceptive, and clearheaded in the face of highly stressful situations.

The control room training exercises utilizing the simulation also allowed for verification of the calibration information contained in the Calibration Information Management System (CIMS) file. When the simulation was used to reverse-engineer a counts value for a desired engineering unit (EU) value, the displayed value in the WATR could be used to test if the calibration information was valid and functional.

While the flight and control room crews benefited from the training sessions, WATR personnel involved were also receiving valuable practice and testing opportunities. Range operations personnel became familiar with the setup and execution of Hyper-X missions, because without these simulated sessions, there would have been few opportunities to practice configuring the control room for end users. The TIE was able to test all 67 control room displays, the derived calculation code, and strip-charts with the simulated PCM stream. Engineers could see their displays "in action" rather than in a static testing mode, and that triggered many modifications to the way data was calculated and displayed to the end user. In the early development of the capability, the ability to record sessions and generate postsession time-history data files proved valuable to the training conductor, TIE, and simulation engineer for testing and verifying the control room training scenarios. Finally, using a simulated PCM stream was the only 
means of verifying the Sim3DApp used for visualization of stack ascent, separation event, HXRV experiment, and HXRV descent into the ocean.

\section{Conclusion}

The capability to simulate multiple telemetry streams and radar data in order to train flight and mission control personnel for a flight project at the NASA Dryden Flight Research Center has been successfully demonstrated. This technology was used to simulate in-flight emergency scenarios for the Hyper-X program and provide a means for the crew to practice several mission profiles.

These training sessions:

- Improved crew response and communications

- Verified and improved control room displays

- Verified calibration coefficients

- Verified operational equipment

- Improved checklists and go/no-go limits

- Resulted in a safer mission.

Crew training via simulated in-flight scenarios in the Dryden Mission Control Centers was an essential part of the preparation for Hyper-X research missions. Control room training was a cost-effective means of ensuring both flight safety and mission success for the Hyper-X air launches. As both the crew and the simulation training team gained familiarity with the capabilities of the system, the fidelity of the training sessions was improved and project personnel were able to perfect their data displays, go/no-go launch conditions, emergency procedures, and the flight cards. The control room training environment served as a nonthreatening place for personnel to learn their roles and practice responding efficiently to highly stressful simulated emergency scenarios. According to Dryden Hyper-X chief engineer Griffin Corpening, "this hard work and training paid off (in the form of) three flawless captive-carry flights and three flawless launch operations."

\section{References}

1. Reubush, D. E., Nguyen, L. T., and Rausch, V. L., "Review of X-43A Return to Flight Activities and Current Status," AIAA-2003-7085, Dec., 2003.

2. X-43A Mishap Investigation Board, "Report of Findings: X-43A Mishap." http://www.nasa.gov/pdf/47414main_x43A_mishap.pdf [cited 25 July 2006].

3.Shy, K. S., Hageman, J. J., and Le, J. H., "The Role of Aircraft Simulation in Improving Flight Safety Through Control Training," NASA/TM-2002-210731, 2002.

4. Fantini, J. A., "Conversion From Engineering Units to Telemetry Counts on Dryden Flight Simulations," NASA/CR1998-206563, 1998.

5. Harris, J., and Downing, B., "WINGS Concept: Present and Future," ITC Proceedings Paper, ITC/USA 2003, Las Vegas, NV, Oct. 2003. 